\title{
Elderly men with a history of distal radius fracture have significantly lower calcaneal bone density and free androgen index than age- matched controls
}

Olof Risto, Ewa Hammar, Karl Hammar, Mats Fredrikson, Mats Hammar and Ola Wahlström

\section{Linköping University Post Print}

N.B.: When citing this work, cite the original article.

Original Publication:

Olof Risto, Ewa Hammar, Karl Hammar, Mats Fredrikson, Mats Hammar and Ola Wahlström, Elderly men with a history of distal radius fracture have significantly lower calcaneal bone density and free androgen index than age-matched controls, 2012, The Aging Male, (15), 1, 59-62.

http://dx.doi.org/10.3109/13685538.2011.593659

Copyright: Informa Healthcare

http://informahealthcare.com/

Postprint available at: Linköping University Electronic Press

http://urn.kb.se/resolve?urn=urn:nbn:se:liu:diva-75464 


\section{Elderly men, with a history of distal radius fracture have significantly lower calcaneal bone density and free androgen index than age-matched controls.}

Olof Risto**, Ewa Hammar*, Karl Hammar*, Mats Fredrikson***, Mats Hammar*, Ola Wahlström**.

*Division of Obstetrics and Gynecology, **Division of Orthopedics, ***Division of Occupational and Environmental Medicine, Department of Clinical and Experimental Medicine, Faculty of Health Sciences, Linköping University, County Council of Östergötland, Linköping, Sweden.

Address for correspondence: Olof Risto, MD., PhD. Division of Orthopedics, Department of Clinical and Experimental Medicine, Faculty of Health Sciences, University Hospital, S-581 85, Linköping, Sweden

+46-13-224173

fax +46-13-224305

e-mail: olof.risto@lio.se

\footnotetext{
Abstract:

Background: Age related bone loss is widely accepted as related to decreased serum-levels of circulating sex hormones. Epidemiological data also show distal radius fractures in men to be a sensitive marker of bone fragility. The aim of this study was to assess if men with a history of distal radius fracture have lower bone mass density (BMD), lower Free Androgen
} 
Olof Risto et al. Testosterone and fractures

Index (FAI), lower total testosterone (T) and lower bio-available testosterone (Bio-T) than healthy age-matched controls.

Patients and methods: A case-control study based on consecutive cases treated for low energy distal radius fracture at our department and age-matched controls.

Thirtynine men, treated between 1997-2004 and 45 age-matched controls underwent calcaneal bone density measurements (t-score) and analyses of $\mathrm{T}$, bio- $\mathrm{T}$ and serum hormone binding globulin (SHBG).

Results: The fracture group had lower BMD $(\mathrm{p}<0.01)$ and lower FAI $(\mathrm{p}=0.01)$. Linear regression analysis showed a correlation between Bio- $\mathrm{T}$ and t-scores $(\mathrm{p}=0.03)$. Using analysis of covariance a significant difference with lower Bio-T in the fracture group was shown.

Conclusion: Bio-T seems to correlate with BMD in elderly men and may serve as a marker for increased fracture risk in this patient group.

\section{Key words:}

Male, Bone Mineral Density, osteoporosis, fractures, testosterone

\section{Introduction:}

Bone mineral density (BMD) decline gradually with age. This age-related bone loss is widely accepted as related to decreased levels of circulating sex hormones. In women there is a rapid decrease of BMD induced by the drop of estrogens around the menopause. In contrast, men experience a slow decline in circulating testosterone (T) levels between 50 and 80 years of age and therefore a more gradual loss of $\operatorname{BMD}(1,2)$. This difference in the kinetics of sexsteroid production over time probably explains the lower prevalence of male age-related osteoporosis. Although more uncommon than female osteoporosis, the average prevalence of osteoporosis for men over 50 years of age is reported to $6 \%$ (3) and in some reports up to $20 \%$ (4). Fractures associated with male osteoporosis carry a higher mortality than does fractures associated with female osteoporosis (5). 
Olof Risto et al. Testosterone and fractures

Several studies have shown total estradiol (E) deficiency, T deficiency and low serum levels of bio-available estradiol (bio-E) to be predictors of male osteoporosis $(6,7,8,9,10)$, a correlation not found for Bio-T in these studies. Results pointing at a more important role of $\mathrm{T}$ in male bone turnover are reported by Fink and co-workers who found total T deficiency to be associated with osteoporosis in men, independent of E levels, and they also found that low levels of total $\mathrm{T}$ and Bio-T appeared to be stronger predictors of rapid bone loss than were low levels of total E and Bio-E (11). Free Testosterone (FT) within normal range has is also recently been found to be an independent positive predictor of BMD in elderly men, and also of both previous and prevalent osteoporosis related fractures in the same group (12). The latter finding makes it of special interest to study elderly men with a history of low energy distal radius fractures.

Since such conflicting results have been reported concerning the impact of $\mathrm{T}$ on male osteoporosis and prevalence of low energy fractures, our aim for this study was to further investigate the relationship between T levels and BMD in elderly men treated for low energy distal radius fractures at our hospital. 
Olof Risto et al. Testosterone and fractures

\section{Material and methods:}

Material: All men older than 54 years of age, treated for distal radius fractures between 19972004 at the Department of Orthopaedics, University Hospital, Linköping, Sweden, were identified $(n=55)$. Age matched controls were chosen from the population register. After exclusion of patients with high energy fractures 39 patients and 45 controls agreed to participate in the study. Information about smoking habits, alcohol consumption and cortisone treatment was obtained by an interview. Body Mass Index (BMI) was calculated as weight/height ${ }^{2}$. Age, alcohol consumption ( $>$ than the equivalence of $5 \mathrm{cl}$ liqour/day), smokers or non-smokers, BMI and use of cortisone medication were included as confounding factors in the statistical analyses.

Methods: Non-fasting venous blood samples were drawn from the antecubital vein, centrifuged and analysed consecutively for: P-Albumine, Serum Sex Hormone Binding Proteine level (S-SHBG) and S-T. Free Androgen Index (FAI) was calculated as the ST/SHBG-ratio and Bio-T was calculated by mass action equations (13). P-Albumin was determined by means of immunochemical technique and turbid metric measurements (Advia 1650, Bayer Sweden AB). S-T was determined by means of B050-201 AutoDELFIA ${ }^{\mathrm{TM}}$ Testosterone kit (Wallac Oy, Åbo, Finland) which is a fluoroimmunotest and S-SHBG was determined by means of a "two-site" fluoroimmunometric test in fixed phase based directly on "sandwich"-technique (B070-101 AutoDELFIA ${ }^{\mathrm{TM}}$ SHBG, Wallac Oy, Åbo, Finland). $\operatorname{BMD}\left(\mathrm{g} / \mathrm{cm}^{2}\right)$ was measured at the calcaneus by dual energy X-ray and laser (DXL) technique with a DXL Calscan (Demetech AB, Solna, Sweden). The precision for DXL Calscan is in vivo $1.5 \% \mathrm{CV}$. T-scores were calculated using the manufacturer's references which is based on a Swedish, Caucasian male population (14). 
Olof Risto et al. Testosterone and fractures

Statistics: Analysis of covariance (ANCOVA), Student's t-test, Fisher's exact test, linear and logistic regression analyses were used for statistical analyses. The level of significance was set to $\mathrm{p}<0.05$. All analyses were performed by Stata v11.1, College Station, Tx, USA.

Ethics: The study was approved by the research ethics board in Linköping.

Every patient and control person was given both written and oral information and gave oral consent to participate. 
Olof Risto et al. Testosterone and fractures

\section{Results:}

The mean age $+/-\mathrm{SD}$ was $70.3 \pm 8.5$ years (fracture group and controls). The mean age in the fracture group was $70.5 \pm 8.8$ years and they had experienced their fracture $4.2 \pm 2.3$ years earlier. The mean age of the controls was $69.7 \pm 8.0$ years.

All variables including t-test results for group statistics (fracture group versus controls) and independent samples tests are summarized in table 1, showing SHBG, FAI, and t-score to differ significantly between the groups, whereas bio-T differed clearly, although not statistically significant (table 1).

Analysis of covariance (ANCOVA), with the confounding factors included, showed a significant difference in Bio-T between the groups, with lower values in the fracture group $\left(\mathrm{F}_{1.72}=5.17, \mathrm{p}=0.03\right)$. This analysis, corrected for $\mathrm{t}$-scores, still showed a tendency, however, not statistically significant $\left(\mathrm{F}_{1.70=1.83}, \mathrm{p}=0.18\right)$. ANCOVA also showed statistically significant differences with regard to fracture for lower FAI $\left(\mathrm{F}_{1.72}=7.17, \mathrm{p}=0.01\right)$ and lower $\mathrm{t}-$ scores $\left(\mathrm{F}_{1.72}=10.18, \mathrm{p}=0.002\right)$ but not for lower $\mathrm{T}\left(\mathrm{F}_{1.72}=0.98, \mathrm{p}=0.33\right)$ for the fracture group compared to the controls.

Linear regression analysis for all study subjects, with confounding factors included, did not show a relationship between total- $T$ and $t$-scores $(B=0.03, p=0.20, r=0.40)$, but a significant relation between Bio- $\mathrm{T}$ and t-scores $(\mathrm{B}=0.12, \mathrm{P}=0.03, \mathrm{r}=0.45)$ (figure 1).

Regression analysis with categorization into $\leq 10^{\text {th }}$ percentile, $11^{\text {th }}$ to $50^{\text {th }}$ percentile and $\geq 51^{\text {th }}$ percentile of all study subjects, regarding Bio-T levels, indicated higher (although not statistically significant) odds ratios for fracture with Bio-T levels below the median. Odds ratios corrected for t-scores were only slightly decreased (table 2). 


\section{Discussion:}

We used calcaneal DXL technique in our study instead of DXA. It has, however, been suggested in comparative studies that the laser technique (DXL) is at least as reliable as the dual energy X-ray technique (DXA). DXL can eliminate fat and other soft tissue both outside and inside the measured bone $(14,15,16,17)$. More than $50 \%$ of male osteoporosis is secondary to life style factors(smoking, alcohol abuse, immobilization) and medical disorders ( hypercorticism, liver or gastrointestinal disorders and hypogonadism) (2). Unfortunately, we did not screen our patients and controls routinely with tests for general diseases, but no patient had a history of major liver or gastrointestinal disease and we corrected the results for life style confounding factors. Therefore, we believe we have succeeded in studying the impact of T on true age-related male osteoporosis.

Interestingly, though not statistically significant, both low weight and smoking are more frequent in the fracture group. This is in accordance with the well known correlation between low weight, smoking and osteoporosis in females. In this study, men with a history of distal radius fractures had statistically significant lower calcaneal BMD- and FAI compared to healthy age-matched controls, whereas no such difference could be found for T. Although not as accurate as FT or Bio-T, especially in men, FAI is still a guide to the free testosterone level (18). Both the low androgen level and the high SHBG level in the fracture group results in the statistically significant difference of free androgen index. The statistically significant difference of SHBG between fracture group and control group motivates studies on the complex control of SHBG production in the liver, insulin resistance, fat metabolism and the metabolic syndrome.

Several studies have shown a clear relationship between serum-levels of E2 and BMD of the male skeleton, but a more uncertain importance of $\mathrm{T}$ or Bio-T $(6,7,8,9,10)$. Our results 
Olof Risto et al. Testosterone and fractures

support findings, showing non-globulin bound serum levels of $\mathrm{T}$ to be an independent predictor of BMD, self-reported previous osteoporosis-related fractures and X-ray verified prevalent vertebral fractures in elderly men (12). Interestingly, Mellström et al. did not find the predictive value of FT below the median to be affected by adjustment for BMD, suggesting the association with fractures to be distinct from the effect on BMD. Cawthone et al. found low Bio-T to be associated with worse frailty status in older men (19). The frailty criteria were: low activity level, exhaustion, weakness, sarcopenia and slowness. Other factors may be muscle strength, BMI and postural balance (20). Previous studies have failed to detect a predictive role of $\mathrm{T}$ for fractures, however, as pointed out by Mellström et al. these studies were all of rather small cohorts of men $(21,22)$. Our analyses of covariance and our regression analyses have confirmed significant relations between low Bio- $\mathrm{T}$, low t-scores and increased risk of sustaining low energy distal radius fractures.

In contrast to some other investigators $(7,9,10)$ our study showed a significant relation between Bio-T and BMD. The study by Mellström and co-workers also showed a strong correlation between the non-globuline bound fraction of T (FT), within normal range, and BMD in their cohort of elderly swedish men (12). By including both FT and Free-E2 values in the same regression models they could establish FT as an independent positive predictor of BMD in male skeletal sites with predominantly cortical bone. It is one of the shortcomings of our study that such an analysis could not be done. The linear regression analysis of Bio-T and t-scores was highly significant in our study, in accordance with Mellström et al. who showed Bio-T within normal levels of variance to be an independent predictor of BMD in men (12). These findings are also in accordance with the results of Gillberg et al.(23), who found FAI and Bio-E2 to be statistically reliable explanatory variables for BMD (23). Although the level of Bio-T was only reduced by $16 \%$, the most probable explanation to the 
Olof Risto et al. Testosterone and fractures

results is the low androgen activity seen in the fracture group.

In conclusion, we have found that men with a history of radiologically documented distal radius fractures have lower calcaneal bone density and lower Bio-T levels, partially because of higher SHBG levels, thereby supporting other findings about the relationship between BioT and BMD To our opinion, an elderly man with a wrist fracture and low Bio-T should urge a BMD test, fracture risk assessment (FRAX), and consequently osteoporosis prevention or treatment. . 
Olof Risto et al. Testosterone and fractures

\section{References:}

1. de Vernejoul MC, Cohen Solal M Estrogens, androgens, and osteoporosis in men. Ann Endocrinol 2003; 64:137-40.

2. Alexandre C. Androgens and bone metabolism. Joint Bone Spine 2005; 72: 202-6.

3. Rochira V, Balestrieri A, Madeo B, Zirilli L, Granata ARM, Carani C. Osteoporosis and male age-related hypogonadism: role of sex steroids on bone (patho)physiology. Eur J Endocrinol 2006; 154: 175-85.

4. Melton LJ III. The prevalence of osteoporosis: gender and racial comparision. Calfic Tissue Int 2001; 69: 179-81.

5. Center JR, Nguyen TV, Schneider D. Mortality after all major types of osteoporotic fractures in men and women: an observational study. Lancet 1999; 353: 878-82.

6. Khosla S, Melton LJ III, Atkinson EJ, O’Fallon WM, Klee GG, Riggs BL. Relationship of Serum sex steroid levels and bone turnover markers with bone mineral density in men and women: A key role for bioavailable Estrogen. J Clin Endocrinol Metab 1998; 83: 2266-74.

7. Khosla S, Melton LJ III, Atkinson EJ, O’Fallon WM. Relationship of serum sex steroid levels to longitudinal changes in young versus elderly men. J Clin Endocrinol Metab 2001; 86: 3555-61.

8. Szulc P, Munoz F, Claustrat B, Garnero P, Marchand F, Duboeuf F, Delmas PD. Bioavailable Estradiol may be an important determinant of osteoporosis in men: The MINOS study. J Clin Endocrinol Metab 2001; 86: 192-9.

9. Gennari L, Merlotti D, Martini G, Gonnelli S, Franci B, Campagna S, Lucani B, Dal Canto N, Valenti R, Gennari C, Nuti R. Longitudinal association between sex hormone levels, bone loss, and bone turnover in elderly men. J Clin Endocrinol Metab 2003; 88: 5327-33. 
Olof Risto et al. Testosterone and fractures

10. van Pottelbergh SG, Kaufman JM. Bioavailable estradiol and an aromatase gene polymorphism are determinants of bone mineral density changes in men over 70 years of age. J Clin Endocrinol Metab 2003; 88: 3075-81.

11. Fink HA, Ewing SK, Ensrud KE, Barret-Connor E, Taylor BC, Cauley JA, Orwoll ES. Association of testosterone and estradiol deficiency with ostoeoporosis and rapid bone loss in older men. J Clin Endocrinol Metab 2006; 91: 3908-15.

12. Mellström D, Johnell O, Ljunggren Ö, Eriksson A-L, Lorentzon M, mallmin M, Holmberg A, Redlund-Johnell I, Orwoll E, Ohlsson C. Free testosterone is an independent predictor of BMD and prevalent fractures in elderly men: MrOS Sweden. J Bone Miner Res 2006; 21: 529-35.

13. Vermeulen A, Verdonck L, Kaufman JM. A critical evaluation of simple methods for the estimation of free testosterone in serum. J Clin Endocrinol Metab 1999; 84:3666-72. 14. Kullenberg R. Reference database for dual X-ray and laser Calscan bone densitometer. J Clin Densitom 2003; 6: 367-72.

15. Hakulinen MA, Saarakkala S, Toyras J, Kroger H, Jurvelin JS. Dual energy X-ray laser measurement of calcaneal bone mineral density. Phys Med Biol 2003; 48: 1741-52. 16. Martini G, Valenti R, Gennari L, Salvadori S, Galli B, Nuti R (2004) Dual X-ray and laser absorptiometry of the calcaneus: comparison with quantitative ultrasound and dualenergy X-ray absorptiometry. J Clin Densitom 2004; 7:349-54.

17. Brismar TB, Janszky I, Toft LI. Calcaneal BMD obtained by Dual X-Ray and Laser predicts future hip fractures - A prospective study on 4398 swedish women. $J$ Osteoporosis 2010; 875647.

18. Morris PD, Malkin CJ, Channer KS, Jones TH. A mathematical comparison of techniques to predict biologically available testosterone in a cohort of 1072 men. Eur J Endocrinol 2004; 151: 241-49. 
Olof Risto et al. Testosterone and fractures

19. Cawthone PM, Ensrud KE, Laughlin GA, Cauley JA, Dam TTL, Barret-Connor E, Fink HA, Hoffman AR, Lau E, Lane NE, Stefanick ML, Cummings SR, Orwell ES. Sexhormones and frailty in older men: The osteoporotic fractures in men (MrOS) study. $J$ Clin Endocrinol Metab 2009; 94(10): 3806-15.

20. Szulc P, Claustrat B, Marchand F, Delmas P D. Increased risk of falls and increased bone resorption in elderly men with partial androgen deficiency: the MINOS study. J Clin Endocrinol Metab 2003; 88:5240-7.

21. Barret-Connor E, Mueller JE, von Muhlen DG, Laughlin GA, Schneider DL, Sartoris DJ. Low levels of estradiol are associated with vertebral fractures in older men but not women: The Rancho Bernardo Study. J Clin Endocrinol Metab 2000; 85: 219-23. 22. Goderie-Plomp HW, van der Klift M, de Ronde W, Hofman A, de Jong FH, Pols HA. Endogenous sex hormones, sex hormone-binding globulin, and the risk of incident vertebral fractures in elderly men and women: The Rotterdam Study. J Clin Endocrinol Metab 2004; 89: 3261-69.

23. Gillberg P, Olofsson H, Mallmin H, Blum WF, Ljunghall S, Nilsson AG. Bone Mineral Density in Femoral Neck is Positively Correlated to Circulating Insulin-Like Growth Factor (IGF)-I and IGF-Binding Protein (IGFBP)-3 in Swedish Men. Calcif Tissue Int 2002; 70:22-9. 
Olof Risto et al. Testosterone and fractures

\section{Tables:}

Table 1.

\begin{tabular}{|l|l|l|l|}
\hline & Control $\mathrm{n}=45$ & Fracture group $\mathrm{n}=39$ & $\mathrm{p}$ \\
\hline Age, years $( \pm$ s.d. $)$ & $70.1( \pm 8.4)$ & $70.5( \pm 8.8)$ & 0.85 \\
\hline Height, $\mathrm{m}( \pm$ s.d. $)$ & $1.79( \pm 0,07)$ & $1.79( \pm 0.07)$ & 0.80 \\
\hline Weigth $\mathrm{kg}( \pm$ s.d. $)$ & $84.3( \pm 12.8)$ & $80.3( \pm 12.7)$ & 0.16 \\
\hline Smoking $(\%)$ & $2(4,7)$ & $6(15.8)$ & $0.14 *$ \\
\hline Alcohol, abuse & 0 & 0 & $0.99 *$ \\
\hline Cortisone use $(\%)$ & $2(4.4)$ & $3(7.7)$ & $0.65 *$ \\
\hline total-T nmol/L( $( \pm$ s.d. $)$ & $15.75( \pm 7.84)$ & $15.30( \pm 6.95)$ & 0.78 \\
\hline Bio-T nmol/L $( \pm$ s.d. $)$ & $6.68( \pm 3.16)$ & $5.62( \pm 2.33)$ & 0.09 \\
\hline SHBG nmol/L $( \pm$ s.d. $)$ & $44.89( \pm 14.10)$ & $53.95( \pm 19.98)$ & 0.02 \\
\hline FAI $( \pm$ s.d. $)$ & $0.38( \pm 0.15)$ & $0.31( \pm 0.11)$ & 0.01 \\
\hline t-score S.D. $( \pm$ s.d. $)$ & $-0.62( \pm 1.18)$ & $-1.56( \pm 1.10)$ & $<0.01$ \\
\hline
\end{tabular}

Fisher's exact test*

Table 2.

\begin{tabular}{|l|l|l|l|}
\hline & $\begin{array}{l}\text { Crude OR } \\
(95 \% \text { CI })\end{array}$ & $\begin{array}{l}\text { Adjusted OR } \\
(95 \% \text { CI })\end{array}$ & $\begin{array}{l}\text { OR also adjusted for t- } \\
\text { score (95\% CI) }\end{array}$ \\
\hline Bio-T<median & $1.48(0.62-3.50)$ & $1.83(0.66-5.09)$ & $1.71(0.60-4.88)$ \\
\hline $\begin{array}{l}\text { Bio-T< }<0^{\text {th }} \text { percentile } \\
\text { of Bio-T }\end{array}$ & $1.51(0.37-6.06)$ & $1.36(0.26-7.10)$ & $1.15(0.21-6.18)$ \\
\hline $\begin{array}{l}\text { Bio-T<10 } \\
\text { of Bio-T compared } \\
\text { with values above } \\
\text { median }\end{array}$ & $1.76(0.41-7.55)$ & $2.07(0.29-14.4)$ & $1.82(0.24-14.0)$ \\
\hline
\end{tabular}


Olof Risto et al. Testosterone and fractures

\section{Legends tables:}

\section{Table 1.}

Anthropometrics, confounding factors, sex-homone variables and t-scores (mean $\pm \mathrm{SD}$ ).

P-values calculated with t-test except where noted.

\section{Table 2.}

Crude and adjusted OR from logistic regression analysis for fractures in relation to Bio-T. Adjusted OR denotes adjusted for anthropometrics and confounding factors. OR also adjusted for t-scores denotes for OR adjusted for anthropometrics, confounding factors and t-scores. 
Olof Risto et al. Testosterone and fractures

Figure 1.

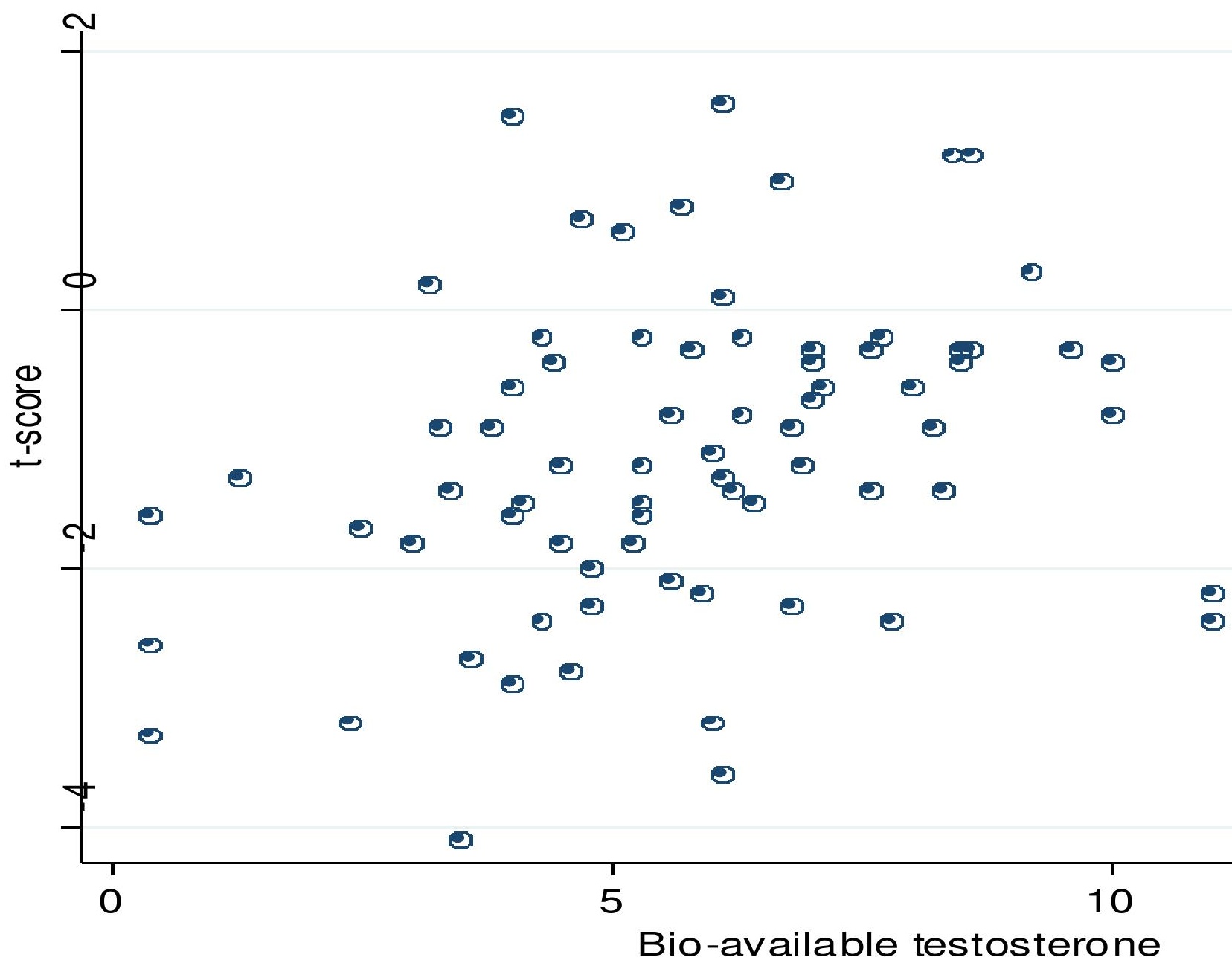

Legend to figure 1:

Scatterplot showing the association between bio-available testosterone and tscore. 
Olof Risto et al. Testosterone and fractures

\section{Acknowledgements:}

The authors gratefully acknowledge the technical assistance of Lotta Lindh-Åstrand, reg.nurse and Ph.D. at the Department of Obstetrics and Gynecology and Inger Ericsson, reg nurse at the department of Orthopaedic Surgery at the University Hospital of Linköping, Sweden. We also acknowledge the financial support from the County Council of Östergötland.

\section{Declaration of interest:}

No interest declared. 
Olof Risto et al. Testosterone and fractures 
Olof Risto et al. Testosterone and fractures 